\title{
Effect of Fascial Distortion Model on the Cobb's Angle in Adolescents with Idiopathic Scoliosis
}

Woo-Jin Lee

Department of Physical Therapy, Gangneung Youngdong University, Gangeung, Korea

Purpose: This study examined the effects of the fascial distortion model (FDM) method on Cobb's angle.

Methods: Fourteen subjects participated in this study. The idiopathic scoliosis group performed FDM treatments eight times in four weeks. A Shapiro-Wilks test was used to verify the normality of a group of idiopathic scoliosis patients. A paired t-test was performed to determine the satisfaction with the normality.

Results: The difference in Cobb's angle was reduced significantly $(p<0.05)$ by an average of $5.72^{\circ} \pm 2.24$ from $15.51^{\circ} \pm 1.81$ before the experiment.

Conclusion: This study found that the use of the FDM method was effective in improving the Cobb's angle. The application of a FDM treatment appears to stabilize the fascia with decreased ability to adapt physiologically. The application of the CD and TB method of FDM treatment improved the asymmetry spine by dispersing moisture in fascia and improving the contraction and relaxation ability. The results suggest that the Cobb's angle is reduced when FDM is applied, thereby preventing the progression of curvature and avoiding psychological and physical problems that can arise from improving patients with scoliosis.

Keywords: Fascial distortion model, Scoliosis, Cobb's angle

서 론

척추옆굽음증은 척추의 3 차원적 변형이다. ${ }^{1}$ Weinstein 등 ${ }^{2}$ 은 AIS (청 소년 특발성 척추옆굽음증)는 10 세 이상에서 호발하며, $\mathrm{Cobb}^{3}$ 은 적 어도 $10^{\circ}$ 의 굽이에서 정의되고 선 자세에서 방사선 촬영하여 Cobb's 테크닉을 사용하여 측정된다고 보고하였다. 선행연구들에 따르면 우 리나라에서 $25-78 \%$ 가 척추에 관련된 질환의 유병률을 보고하였으 며, 척추옆굽음증은 2-3\% 정도가 10-16세 학생에서 진단되고 $10^{\circ}$ 이하 에서는 남녀의 비율은 비슷하나 10-30 사이의 비율은 여성에게서 높은 것으로 보고되고 있다. ${ }^{4,5}$ 특히 청소년기에는 근육뼈대계가 빠르 게 성장하며 오랫동안 앉아서 생활하는 시간이 길고, 책상 및 의자 등 좋지 못한 학습 여건과 부족한 운동량, 핸드폰의 지나친 사용 등 이 척추에 부정적인 영향을 줄 수 있다. ${ }^{6}$ Moon 등근 척추 옆굽음증 의 굽이가 낮을수록 치료 효과가 좋기 때문에 조기에 발견하여 치료 를 받아야 한다고 하였으나, 전체 옆굽음증 환자 중 $10 \%$ 정도 만이 옆 굽음증을 위한 치료를 받고 있으며 $90 \%$ 에 달하는 환자는 해마다 반

Received Jan 3, 2019 Revised Feb 13, 2019

Accepted Feb 14., 2019

Corresponding author Woo-Jin Lee

E-mail marin66@hanmail.net
복되는 검사를 통해 예후만이 관찰되고 있다. ${ }^{8}$

현재 특발성으로 인한 척추옆굽음증의 치료는 외과적 방법과 보 존적 방법으로 실시되고 있다.9 Moon 등 ${ }^{10}$ 은 옆굽음증의 굽이가 $40^{\circ}$ 보다 클 때에는 수술 등 외과적 치료법이 검토되나, 초기에 발견한 환 자는 물리치료 등 보전적 방법으로 치료가 가능하다고 하였다. 또한 대부분의 환자는 자세운동 등 보존적 방법을 통해서 증상이 호전되 며, 보조기 및 외과적 시술을 요하는 경우는 많지 않다." ${ }^{11}$ LehnertSchroth ${ }^{12}$ 는 척추옆굽음증은 발과 다리, 골반으로부터 위쪽으로 전달 되는 힘의 좌우 불균형이 있으며, 영향을 받게 되는 근육은 이마면에 서 중심선이 벗어나는 범위에 비례하여 그 길이가 길어지나, 그 부피 는 반비례하여 작고 약하게 된다. 강하게 수축하고 있는 것처럼 보이 는 오목한 방향의 근육들 역시 볼록한 방향으로 과도하게 신장된 근 육들만큼이나 비효율적이며, 볼록한 쪽의 근육은 두꺼워지지만 힘 이 증가하는 것은 아니며 수축하는 능력이 저하되어 있고, 오목한 쪽 의 근육은 짧아지고 근전도 검사에서 비활동적인 것으로 나타나며 옆굽음증이 증가할수록 기능은 감소한 것으로 보이나 이완하는 능 Attribution Non-commercial License (Http:// creativecommons.org/license/by-nc/4.o.) which permits unrestricted non-commercial use, distribution, and reproduction in any medium, provided the original work is properly cited. 
력의 저하로 인해 더욱 비효율적으로 변화한 것으로 생각된다고 보 고하였다.

Travell과 Simons ${ }^{13}$ 은 되풀이되어 발생하는 만성적인 외상으로 인하 여 근막은 다양한 상태로 변화하게 되는데, 이러한 변화는 기능 장애 와 비정상화를 초래한다고 보고하였다. 근막은 인체의 모든 근육뿐 아니라 다른 내부 장기를 포함한 모든 기관과 서로 연결되어 형태를 유지해주는 조직이며 근섬유, 인대, 힘줄 등을 싸고 있는 등 여러 형태 를 가진다. 또한 뼈와 신경을 분리하고, 보호하며 완충하는 등 다양한 기능을 수행하며, ${ }^{14,15}$ 비정상적인 외력이 가해질 경우에 스스로 수축 함으로써 신체를 보호하지만 한편 이것으로 인해 근막이 싸고 있는 조직이나 기관의 기능부전을 초래할 수도 있다. 따라서 근막이 손상 됨으로 인해 생리적 적응력이 낮아지고 근막의 긴장도는 높아질 수 있으며, 긴장도는 다른 부분으로 넓게 퍼지면서 기능 제한, 통증, 외상 등으로 나타나며 유연성과 연속성이 상실된다고 보고 하였다. ${ }^{16}$

Typaldos $^{14}$ 는 근육뼈대계의 손상을 근막 변형의 몇 가지 유형으로 설명하고 있다. 근육을 싸고 있는 근막, 힘줄이나 인대, 관절을 둘러싸 고 있는 근막에서 발생되는 근막의 여러 변형 형태를 나타내게 된다 는 근막 변형 모델(fascial distortion model)을 보고하였다. FDM은 환 자가 나타내는 신체적 언어(body language)를 통하여 통증이나 기능 부전의 원인을 평가하고, 손이나 도구를 이용하여 근막의 변형을 정 상적으로 회복시키는 평가방법이자 치료방법이다. ${ }^{17} \mathrm{FDM}$ 에서 인대 와 힘줄, 관절주머니와 뼈 사이를 연결해 주는 부분을 전이영역(transition zone, TZ)이라고 정의하고 있으며, TZ에 비효율성이 증가하면, 근막은 continuum distortions $(\mathrm{CD})$ 형태로 바뀐다고 정의되며, 뼈나 인대로의 한쪽 방향으로 힘이 순간적으로 발생할 때 전이영역(transition zone)에서의 전이력이 상실된 상태가 나타나는 것이 CD이며, 전 이력이 상실된 결과로 그 부분의 근막은 매우 단단해져 촉진 시 쌀알 모양의 형태(grain of rice)로 주변 조직들의 기능을 방해하며, 고유수 용성감각에 영향을 미치게 된다고 하였다. ${ }^{17}$ 또한 척추는 다양한 손 상으로 근막 변형이 올 수 있는데 오랜 기간의 척추에 가해지는 압박 으로 인하여 척추세움근 주변을 따라 trigger bend (TB) 형태의 근막 변형이 발생한다고 하였으며, $\mathrm{TB}$ 는 근육을 보호하기 위하여 근막이 찟어지거나 뒤틀리는 상태이며 치료방법은 단단해지고 기능을 방해 하는 근막을 강한 물리적 압박으로 인해 제거하여 손상된 부위의 근 막을 풀어주고 찢어지거나 겹쳐진 근막을 다시 원상태로 결합시켜주 는 것이라고 하였다. ${ }^{14}$

따라서 본 연구에서는 이전의 연구들에서 다루어지지 않았던 뼈와 인대 사이의 전이 영역의 기능을 개선하는 $\mathrm{FDM}$ 의 $\mathrm{CD}, \mathrm{TB}$ 방법이 옆 굽음증을 가진 환자의 굽이 개선에 미치는 영향을 알아보고자 한다.

\section{연구 방법}

\section{1. 연구 대상}

본 연구에서는 등뼈의 오른쪽 굽이가 있는 $\mathrm{S}$ 형태의 특발성 척추옆굽 음증 진단을 받은 4-6학년 초등학생 14명을 대상으로 하였다. 대상자 는 아담의 앞쪽 굽힘 검사(Adams forward bending test)에서 갈비뼈의 돌출과, 좌우 어깨뼈에서 높이 차가 있는 학생으로 하였고, 척추 전장 전후방 방사선 사진을 촬영하였다. 방사선 사진에서 굽이의 각도가 10-20인 대상자 중 현재 보존적 치료를 받지 않으며 허리 통증이 없 는 14명을 대상으로 하였다. 연구기간은 2018년 9월 2일부터 11월 30일 까지 대상자 1 인 기준으로 주 2 회씩, 4 주에 걸쳐 총 8 회를 실시하였다. 모든 연구 대상자는 실험하기 전에 본 연구에 대한 목적과 치료방법 에 대한 설명을 듣고 대상자와 대상자의 부모님은 자발적으로 실험 에 동의하였다. 대상자의 선별 기준은 균형에 영향을 줄 수 있는 신체 적인 결함이나 신경학적 문제가 없는 자로 선정하였으며, 결과에 영 향을 줄수 있는 척추수술 경험자는 연구에서 제외하였다.

\section{2. 실험 방법}

\section{1) 측정도구 및 방법}

본 연구에서는 Cobb's angle의 측정을 위해 X-ray촬영을 사용하였다. 바로 선 자세에서 척추 전장 전후방(AP view of whole spine) 사진을 촬 영하였으며, Cobb`s method를 이용하여 Cobb’s angle을 측정하였다.

\section{2) 실험절차}

모든 대상자들은 같은 물리치료사에게 관찰되었고 FDM방법으로 치료를 받았다. 치료사는 대상자를 엎드린 자세로 척추의 굽이가 있 는 좌우측 지점들을 posterior anterior $(\mathrm{PA})$ 방향으로 압력을 주어 척 추 및 척추갈비관절(costovertebral articulation)의 움직임이 저하된 부 분에 $\mathrm{CD}$ 지점을 찾았으며, 또한 대상자의 통증이 있는 부분을 찾아 엄지손가락의 손가락 끝으로 강한 국소 압박을 가했고, 대상자가 통 증이 없어졌다고 말했을 때 압박을 줄였다. 이러한 절차는 대상자가 더 이상의 통증이 없고 편안함을 느낄 때까지 반복하였으며, ${ }^{17}$ 치료 의 끝은 손가락 끝의 강한 압박으로 뒤통수(occipital)에서 엉덩뼈 능 선(iliac crest)까지 쓸어내렸다.

\section{3) 자료분석}

대상자들의 Cobb's angle 측정값의 전후 차는 대응표본 t검정(paired ttest)를 사용하여 비교하였다. 수집된 측정값의 분석은 SPSS Statistics version 20을 이용하였으며, 통계학적 유의수준을 검증하기 위하여 $\mathrm{p}<0.05$ 로 설정하였다. 
Table 1. Anthropometric data

$(n=14)$

\begin{tabular}{lc}
\hline Variable & Total \\
\hline SEX & \\
M & 8 \\
F & 6 \\
Age (yr) & $11.9 \pm 0.73^{\mathrm{a}}$ \\
Height $(\mathrm{cm})$ & $147.4 \pm 6.94$ \\
Weight $(\mathrm{kg})$ & $42.5 \pm 8.22$ \\
\hline
\end{tabular}

aMean \pm standard deviation.

결 과

\section{1. 연구 대상자의 일반적 특성}

본 연구에 참여한 대상자는 특발성 척추옆굽음증으로 진단받은 14 명이 실험에 참가하였다. 평균나이는 11.9 세, 체중 $42.5 \mathrm{~kg}$ 그리고 신장 은 $147.4 \mathrm{~cm}$ 였다(Table 1).

\section{Cobb's angle 분석}

본 연구에 참여한 대상자들은 선 자세에서 X-ray검사를 하였고 Cobb'각이 $10^{\circ}$ 이상, 아담스전방굴곡 검사에서 간이 scoliometer로 몸통 회전각이 $5^{\circ}$ 이상인 학생을 선발하였다. 변수의 정규성 검증을 위해 Shapiro-Wilks 검정을 시행하였고, 그 결과 정규성을 만족하여 대응표본 t검정(paired t-test)을 실시하였다. 4 주간 8 회의 FDM 치료 후 Cobb's angle의 차이는 실험 전 $15.51^{\circ} \pm 1.81$ 에서 실험 후 $9.78^{\circ} \pm 3.61$ 로 평균 $5.72^{\circ} \pm 2.24$ 감소하였으며 통계학적으로 유의한 차이를 보였다 $(\mathrm{p}<0.05)($ Table 2$)$.

\section{고 찰}

본 연구는 특발성 척추옆굽음증 환자를 대상으로 몸통의 자세 문제 를 해결하기 위하여 FDM을 적용함으로써 Cobb's각에 미치는 영향 을 알아보기 위하여 실시하였다. Cobb's angle은 옆굽음증의 굽이가 오목한 방향으로 가장 많이 기운 위쪽의 척추골과 아래쪽의 척추골 을 각각 선택하고, 위쪽 척추골의 윗면을 따라 그은 선과 아래쪽 척추 골의 아래면을 따라 그은 선에 수직하는 두 선이 교차되어 이루는 각 이다. ${ }^{18}$ 초등학교 건강검진을 통해 조기에 척추옆굽음증을 발견하고 조기에 치료함으로써 척추수술은 감소했다고 보고하였으며, 따라서 간단한 검사를 통한 조기 진단과 적절하고 지속적인 재활 운동의 실 시가 필요할 것으로 보고하였다. ${ }^{1921} \mathrm{Yu}$ 와 Jung $\mathrm{J}^{20}$ 은 척추옆굽음증에 관 한 국내 연구를 바탕으로 보존적 치료를 운동, '운동치료', '운동요법'을 운동치료, '견인치료', ‘열 전기치료'는 물리치료, '교정' 및 '추나는 추나 및 교정요법으로 분류하여 성장기 청소년들에게서 모든 보존적 치료 는 척추옆굽음증의 감소에 효과가 있는 것으로 나타났고 빠른 조기
Table 2. Comparison of Cobb's angle

(Unit: degree)

\begin{tabular}{ccccc}
\hline & $C B$ (pre) & $C B$ (post) & $t$ & $p$ \\
\hline FDMT $(n=14)$ & $15.51 \pm 1.81^{\text {a }}$ & $9.78 \pm 3.61$ & 9.56 & 0.001 \\
\hline
\end{tabular}

aMean \pm standard deviation

CB: Cobb's angle, FDMT: Fascial distortion model therapy.

발견은 즉각적인 보존적 치료로 이어질 수 있으며 이는 청소년들의 척 추 옆굽음증의 진행을 억제할 수 있을 것이라고 보고하였다.

현재까지 척추옆굽음증 환자의 기능 증진을 위한 다양한 치료방 법이 연구되어 왔지만, 근막 변형 형태를 조정하는 치료방법의 연구 는 많지 않다. John 등 22 은 3 차원의 투명한 흰색을 띠는 튼튼한 결합조 직인 근막을 얕은 층(superficial)으로부터 깊은 층(deep)과 가장 깊은 층(deepest)으로 분류했다. 얕은 층은 진피의 아래에 위치하며, 깊은 층은 근육이나 뼈, 신경이나 혈관 또는 내장을 싸고 있는 것이라 하였 다. 근막은 모든 기관들의 형태를 보존하고 제 위치에 있도록 하고, 신 체에 가해지는 물리력에 대하여 기관을 보호하는 역할을 가진다고 하였으며, ${ }^{23}$ 근막 손상 시에 생체 역학적 자극은 수용기들에 의해 중 추신경계로 전달되고, 중추신경계의 조절능력과 수용기의 적응능력 은 신경통합에 의해 결합조직의 손상이 지속되는 기간을 결정한다 고 하였다. ${ }^{24}$ Typaldos ${ }^{14}$ 는 근막에 비정상적으로 압력을 가하게 되는 외상, 염증, 자세로 인하여 통증이나 기능부전 등의 증상이 유발될 수 있다고 보고하였다. 척추옆굽증은 불균형한 자세를 만들게 되고 이로 인한 시각과 자세변화에 미치는 영향이 크며, 25,26 근막은 비정상 적으로 압박될 때 통증과 기능적인 문제가 발생될 수 있으므로 해당 부위에 물리적으로 강한 압력을 가함으로써 손상된 근막을 풀어주 거나 다시 붙여주는 것이 근 재교육이라 하였다. ${ }^{14}$

본 연구에서는 척추옆굽음증 환자에게 변형된 근막을 조정하는 FDM치료를 적용했을 때 Cobb's angle의 변화가 어떻게 나타나는 지 에 대해 알아보고자 하였다. 그 결과 특발성 척추옆굽음증 환자의 Cobb's angle은 실험 전 $15.51^{\circ} \pm 1.81$ 에서 실험 후 $9.78^{\circ} \pm 3.61$ 로 평균 $5.72^{\circ} \pm 2.24$ 감소되었으며 통계학적으로 유의한 차이를 보였다. Chaitow $^{28}$ 는 인체를 구성하는 근막에 자극이 주어지면 기계적 수용기들 (mechanoreceptors)이 반응하여 근육 수축에 관여하는 $\mathrm{H}$ 반사를 억 제하면서 근육과 근막이 이완된다고 하였으며 수분의 부족으로 점 탄성이 부족한 근막의 수분을 분산시켜 유연성을 증가시킨다고 하였 다. ${ }^{27}$ 척추옆굽음증 $\mathrm{FDM}$ 치료의 $\mathrm{CD}$ 와 $\mathrm{TB}$ 방법의 적용은 볼록한 부위 의 두꺼워진 근육의 수축을 제한하고 있는 근막과 오목한 방향의 이 완을 제한하고 있는 근막에 물리적 압박을 통해 생리학적으로 적응 하는 능력을 점차적으로 활성화 시켜주었으며, 그 결과 몸통의 근막 에 수분을 분산시키고 수축과 이완 능력을 향상시켜 비대칭성과 척 추 몸통 굽이가 개선되었을 것으로 사료된다. 따라서 척추옆굽음증 환자에게 FDM치료법을 적용하는 것은 Cobb's angle을 감소시킴으로 
써 척추옆굽음증을 치료함은 물론이고 성장기 청소년의 심리적인 문 제를 예방할 수 있을 것으로 기대한다. 또한 오랜 기간의 재활운동과 치료가 필요한 성장기 척추옆굽음증 환자들의 몸통근육을 활성화 시키고 척추의 비정상적 척추옆굽이의 개선 및 증진시키는 방법으로 $\mathrm{FDM}$ 치료를 제안하고자 한다. 본 연구는 경증의 성장기 청소년 척추 옆굽음증 환자 14 명을 대상으로 하였고, 대조군 설정 없이 실험군의 실험 전후 비교만을 실시하였으며, 기능적 변화를 관찰할 수 있는 $\mathrm{ROM}$, 근력 등의 변수 설정이 적용되지 않아 그 결과를 일반화하기에 제한이 있다. 향후 연구에서는 성인 대상자 및 객관적인 측정도구를 이용한 척추옆굽음증 환자의 심부 근력과 표면근력 증가 및 심폐 기 능에 미치는 영향을 조사하는 연구가 필요할 것으로 생각한다. 또한 근막 변형 모델 치료를 다양한 대상자에 적용하여 얼마나 효과가 있 는지를 조사한다면 더 많은 환자들의 삶을 질을 높이는데 기여할 수 있을 것으로 기대된다.

\section{REFERENCES}

1. Parent S, Newton PO, Wenger DR. Adolescent idiopathic scoliosis: etiology, anatomy, natural history, and bracing. Instr. Course Lect. 2005;54: 529-36.

2. Weinstein SL, Dolan LA, Cheng JC et al. Adolescent idiopathic scoliosis. Lancet 2008;371:1527-37.

3. Cobb JR. Outline for the study of scoliosis. Am Acad of Ortho Surg Inst Lect. 1948;5:261-75.

4. Yi SJ. Oswestry low back pain disability index and related factors in patients with low back pain. J Kor Phys Ther. 2008;20(4):21-8.

5. Lenssinck ML, Frijlink AC, Berger MY et al. Effect of bracing and other conservative interventions in the treatment of idiopathic scoliosis in adolescents: a systematic review ofclinical trials. Phys Ther. 2005;85(12): 1329-39.

6. HwangBo PN. Psychological and physical effects of Schroth and Pilates exercise on female high school students with idiopathic scoliosis. J Kor Phys Ther. 2016;28(6):364-8.

7. Moon JH, Kang SW, Lee JS et al. The effects of rehabilitation program in adolescent scoliosis. J of korean Rehap. 1996;20(2):424-32.

8. Haasbeek JF. Adolescent idiopathic scoliosis. Postgrad Med. 1997;101(6): 207-9, 215-6.

9. Focarile FA, Bonaldi A, Giarolo M et al. Effectiveness of nonsurgical treatment for idiopathic scoliosis: Overview of available evidence. Spine. 1991;16(4):395-401.

10. Moon JH, Gang MJ, Gang SG et al. Evaluation of spinal deformity in Korean female high school student. ARM. 1995;19(4):846-52.

11. Bettany-Saltikov J, Parent E, Romano M, et al. Physiotherapeutic scoliosis specific exercises for adolescents with idiopathic scoliosis. Eur J Phys Rehabil Med. 2014;50(1):111-21.

12. Lehnert Schroth CH. Dreidimensionale Skoliosebehandlung. Munich, Urban \& Fischer. 2007;52-7.

13. Travell JG, Simons DG. Myofascial pain and dysfunction: the trigger point manual, the upper extremities. Baltimore, Williams\& Wilkins.1983;5-90.

14. Typaldos S. Clinical and theoretical application of the Fascial Distortion Model within the practice of medicine and surgery. USA, Orthopatic global health pubns. 2002;3-60.

15. Tiidus PM. Massage and ultrasound as therapeutic modalities in exercise-induced muscle damage. Can Journal Appl Physiol. 1999;24(3):26778.

16. Ham YW. Myofascial release for muscle tension. Journal of allied health reserch. 1999;(8):15-25

17. European FDM Association. Das Faszien distorsions modell (FDM) nach Stephan Typaldos D.O. Die Typaldos-Methode, Bramsche, EFDMA, 2014

18. Orthopaedics. Modern medicine. The korean orthopaedic association. 1996:364-373.

19. Lonstein JE, Bjorklund S, Wanninger MH. Voluntary school screening for scoliosis in minnesota. J Bone Joint Surg. 1982;64-A:481-488.

20. Yu JH, Jung SM. Effects of conservative treatment on scoliosis according to early detection. J Kor Phys Ther. 2010;22(4):65-71.

21. Hong EJ, Cho SH, Hwangbo K, The Influence of Adolescent's Scoliosis on Stress and Study-attitude. J Kor Phys Ther. 2012;24(1):15-21

22. John FB, Barnes, Rsi TA. myofascial release seminars. 1991.

23. Scott J. Molecules that keep you in shape. New Scientist. 1986;111:49-53.

24. Seo HK, Kong WT, Lee SY. The effect of myofacial release and transcutaneous electrical nerve stimulation on the range of motion and pain in patient with chronic cervical neck pain. Journal of Korean Academy of Orthopedic Manual Therapy. 2005;11(2):1-12.

25. Seo SK, Kim SH, Kim TY. Evaluation of static balance in postural tasks and visual cue in normal subjects. J Kor Phys Ther. 2009;21(4):51-6.

26. Yoon NM, Yoon HJ, Kim G. Effect of the Type and Positon of Scoliosis on the Static Balance of Adolescents. J Kor Phys Ther. 2017;29(5):28791.

27. Chaitow L. Research in the water and fascia: Micro-tornadoes, hydrogenated diamonds \& nanocrystals. Massage Today. 2009;9(6). 